\title{
Volatile Compound Screening Using HS-SPME-GC/MS on Saccharomyces eubayanus Strains under Low-Temperature Pilsner Wort Fermentation
}

\author{
Kamila Urbina ${ }^{1,2,+}$, Pablo Villarreal ${ }^{1,2,+}$, Roberto F. Nespolo ${ }^{2,3,4}$, Ricardo Salazar ${ }^{5}$, \\ Rocio Santander ${ }^{6}$ and Francisco A. Cubillos $1,2, *$ (D) \\ 1 Departamento de Biología, Facultad de Química y Biología, Universidad de Santiago de Chile, \\ 9160000 Santiago, Chile; kamila.urbina@usach.cl (K.U.); pablo.villarreal.d@usach.cl (P.V.) \\ 2 Millennium Institute for Integrative Biology (iBio), 7500565 Santiago, Chile; robertonespolorossi@gmail.com \\ 3 Instituto de Ciencias Ambientales y Evolutivas, Universidad Austral de Chile, 5090000 Valdivia, Chile \\ 4 Center of Applied Ecology and Sustainability (CAPES), 8331150 Santiago, Chile \\ 5 Laboratorio de Electroquímica del Medio Ambiente, LEQMA, Departamento de Química de los Materiales, \\ Facultad de Química y Biología, Universidad de Santiago de Chile, 9160000 Santiago, Chile; \\ ricardo.salazar@usach.cl \\ 6 Laboratorio de Cinética y Fotoquímica, Departamento de Ciencias del Ambiente, Facultad de Química y \\ Biología, Universidad de Santiago de Chile, 9160000 Santiago, Chile; rocio.santanderm@usach.cl \\ * Correspondence: francisco.cubillos.r@usach.cl \\ + These authors contributed equally to this work.
}

Received: 21 April 2020; Accepted: 15 May 2020; Published: 18 May 2020

\begin{abstract}
The recent isolation of the yeast Saccharomyces eubayanus has opened new avenues in the brewing industry. Recent studies characterized the production of volatile compounds in a handful set of isolates, utilizing a limited set of internal standards, representing insufficient evidence into the ability of the species to produce new and diverse aromas in beer. Using Headspace solid-phase microextraction followed by gas chromatography-mass spectrometry (HS-SPME-GC-MS), we characterized for the first time the production of volatile compounds in 10 wild strains under fermentative brewing conditions and compared them to a commercial lager yeast. S. eubayanus produces a higher number of volatile compounds compared to lager yeast, including acetate and ethyl esters, together with higher alcohols and phenols. Many of the compounds identified in S. eubayanus are related to fruit and floral flavors, which were absent in the commercial lager yeast ferment. Interestingly, we found a significant strain $\times$ temperature interaction, in terms of the profiles of volatile compounds, where some strains produced significantly greater levels of esters and higher alcohols. In contrast, other isolates preferentially yielded phenols, depending on the fermentation temperature. This work demonstrates the profound fermentation product differences between different $S$. eubayanus strains, highlighting the enormous potential of this yeast to produce new styles of lager beers.
\end{abstract}

Keywords: yeast; volatile compounds; S. eubayanus; beer; lager

\section{Introduction}

Beer is the most popular and widespread alcoholic drink in the world, offering a wide variety of styles and flavors around the globe [1]. The production of this beverage is determined by well-defined processes, such as malting, grinding and macerating the grains, cooking the wort, and finally fermenting [2]. The final fermented product contains unique organoleptic properties, as a result of 
a delicate balance between aromas and flavors provided by the main ingredients used during the process: malt, water, hops, and yeast $[3,4]$.

Industrial beer production is dominated by yeasts belonging to the Saccharomyces genus, mainly Saccharomyces cerevisiae responsible for ale beer fermentation, while S. pastorianus (a hybrid between S. cerevisiae $\times$ S. eubayanus) is used for lager beers. Unlike ales, which are fermented by S. cerevisiae in a range of $16-25^{\circ} \mathrm{C}$, lagers are fermented by $S$. pastorianus at lower temperatures $\left(8-15{ }^{\circ} \mathrm{C}\right)$, mostly because of the cryotolerant contribution of $S$. eubayanus to the lager hybrid [5]. Lager beer represents more than $90 \%$ of the beer produced worldwide and is the most popular style consumed [6]. During fermentation, yeast cells produce a wide range of secondary metabolites, including volatile compounds (VCs) responsible for the complex flavors and aromas found in beer. VCs are molecules with low molecular weight and rapid dispersion in the environment and determine the different organoleptic qualities of beer $[7,8]$. Some of the VCs found in beer are synthesized by yeast cells through several metabolic pathways, emphasizing that a significant contribution to the organoleptic properties of beer is provided by the particular strain used for fermentation [2]. Hence, the strains' genotype, together with environmental factors during fermentation, determines to a large extent the presence of these compounds in the final product [9]. For example, S. pastorianus (employed in the production of Pilsner-style lager) [10,11] produces at low temperatures a subtle organoleptic profile mainly characterized by the presence of ester compounds such as ethyl acetate, ethyl hexanoate, and isoamyl acetate. On the other hand, S. cerevisiae (employed to produce ale craft beer fermented at high temperatures compared to lager) $[10,11]$ produces a wider range of VCs like $\beta$-myrcene, ethyl octanoate, $\beta$-linalool, ethyl decanoate, octanoic acid, decanoic acid, ethyl acetate, and ethyl propionate, among others, providing a more complex organoleptic profile in beer [11,12]. The environmental stresses faced during the fermentation process, such as the presence of spoilage microorganisms, the fermentation temperature, nitrogen availability, and carbon sources in the wort, also impact the VC profile of the beer [2,7]. Therefore, depending on these variables, yeast cells produce different concentrations and types of VCs, allowing them to regulate their metabolism in terms of nitrogen uptake, membrane fluidity, and biomass generation $[1,6]$.

The most relevant VCs produced by yeast are esters, phenols, and alcohols derived from the Ehrlich route $[2,10]$. However, most of the strains used in beer fermentation produce very similar and smooth organoleptic profiles, as found in many lager beers. While ale beers are marked by a broad array of esters and higher alcohols [1], lagers are generally characterized by a limited set of flavors and aromas [13]. For example, two commercial lager strains (Frisinga-TUM 3470 and Securitas-TUM 193) produced fewer esters and higher alcohols compared to a set of ale strains [14]. Interestingly, this set of ale strains showed different VC production profiles, demonstrating a pervasive intra-specific phenotypic variability among ale strains and a considerable impact on the final fermented product [14]. The lack of a wide range of VCs in lager styles is mostly explained by the low genetic diversity among S. pastorianus strains, strongly limiting the variety of lager styles. Consequently, the identification of new strains able to provide unique organoleptic profiles is an interesting approximation to expand the repertoire of lager beers and address the demands for new beer styles with different alcohol content and new sensory profiles $[15,16]$.

A novel wild yeast with the capacity to be used in the brewing industry is S. eubayanus. The isolation of this cryotolerant yeast was initially reported by Libkind et al., 2011 [17] from Nothofagus forests in Argentina, and since then, it has been found in North America [18,19], East Asia [20], New Zealand [21], and, most recently, in Chile [22]. Interestingly, recent reports have shown considerable diversity of S. eubayanus in Patagonia $[19,22]$. Moreover, Patagonian strains exhibited significantly different fermentative profiles depending on the latitude from where the strains were obtained, in that isolates from northern Patagonian populations showed a better fermentative performance compared to isolates obtained from southern Patagonia and North American populations. However, in general, S. eubayanus attenuation levels were lower compared to the $S$. pastorianus W34/70 commercial strain, yet some strains still showed commercially accepted attenuation levels [22]. In this context, S. eubayanus has caught the 
interest of researchers and beer producers given the novel fermentative properties, such as fermentation at low temperatures $\left(12{ }^{\circ} \mathrm{C}\right)$, efficient maltose utilization, and production of VCs (e.g., volatile-esters) that are pleasant in the final product [6]. Despite these attractive traits, the phenotypic diversity associated with the production of VCs among S. eubayanus isolates in wort fermentation has not been thoroughly characterized, constraining the potential utilization and knowledge of these yeasts. Furthermore, VC production in the S. eubayanus type strain has only been performed using HS-GC-FID (headspace gas chromatography with flame-ionization detector), where few VCs were quantified using internal standards [6,23]. Alternative approaches, such as HS-SPME-GC-MS (headspace solid-phase microextraction followed by gas chromatography-mass spectrometry), allows identifying a wider set of VCs whose identity is unknown before analysis. Furthermore, using this approach, relative ratios between samples can be compared, representing an alternative for brewing to identify potential novel aromas and flavors in beer.

In this study, we sought to investigate and characterize for the first time the fermentative and VC profile of different $S$. eubayanus strains from different Patagonian localities under fermentative conditions at low temperature $\left(12{ }^{\circ} \mathrm{C}\right)$. To accomplish this, micro-fermentations were screened using the headspace solid-phase microextraction followed by gas chromatography-mass spectrometry method (HS-SPME-GC-MS) as a sensitive analytical means to identify VCs. The data gathered here demonstrate that a broad array of VCs is produced by wild S. eubayanus yeasts and highlights the potential of new strains for lager beer fermentation.

\section{Materials and Methods}

\subsection{Yeast Strains Used in this Study}

The S. eubayanus strains used in this study were obtained from bark samples from Nothofagus pumilio trees (lenga) collected in 10 different localities in Chile. All the strains were previously identified and described by Nespolo et al., 2020 [22] (Table S1). Briefly, strains were isolated from approximately $1 \mathrm{~g}$ of bark samples and immediately incubated in a $15 \mathrm{~mL}$ tubes containing $10 \mathrm{~mL}$ of enrichment media. This media contained: $2 \%$ yeast nitrogen base, $1 \%$ raffinose, $2 \%$ peptone, and $8 \%$ ethanol [24]. Samples were incubated for two weeks at $20{ }^{\circ} \mathrm{C}$ without agitation and were subsequently vortexed and plated $(5 \mu \mathrm{L})$ onto YPD agar (1\% yeast extract, $2 \%$ peptone, $2 \%$ glucose, and $2 \%$ agar). Isolated colonies were stored in glycerol $20 \% v / v$ and stored at $-80{ }^{\circ} \mathrm{C}$ in the Molecular Genetics Laboratory yeast collection at Universidad de Santiago de Chile. The strains are available upon request.

\subsection{Micro-Fermentation Assay}

Micro-fermentation assays were performed on two genetically different S. eubayanus isolates from each location (Table S1). The different fermentations were made in beer wort "Pilsner Connoisseur" (Muntons), which was sterilized at $100{ }^{\circ} \mathrm{C}$ for $25 \mathrm{~min}$. An initial inoculum of $5 \mathrm{~mL}$ was prepared in $6^{\circ} \mathrm{P}$ beer wort, where a single colony from each strain was used. The sample was incubated for $24 \mathrm{~h}$ at $20^{\circ} \mathrm{C}$ in constant agitation at $150 \mathrm{rpm}$. Subsequently, the inoculum was transferred to $50 \mathrm{~mL}$ of $12{ }^{\circ} \mathrm{P}$ beer wort and kept at $20^{\circ} \mathrm{C}$ with shaking at $150 \mathrm{rpm}$ for another $24 \mathrm{~h}$. The cell cultures obtained were centrifuged at $5000 \mathrm{rpm}$ for $5 \mathrm{~min}$ and used to calculate the final cell concentration for use in each micro-fermentation, according to the formula described by White and Zainasheff [25]. The micro-fermentation assay was performed in triplicate in $50 \mathrm{~mL}$ of previously oxygenated $(15 \mathrm{mg} / \mathrm{L})$ $12{ }^{\circ} \mathrm{P}$ beer wort and supplemented with $0.3 \mathrm{ppm}$ of $\mathrm{ZnCl}_{2}$. Airlocks with $30 \%$ of glycerol were used. The weight of the bottles was measured throughout the progress of the fermentation process, registering on an analytical balance the $\mathrm{CO}_{2}$ loss over time $(\mathrm{g} / \mathrm{L})$. The commercial strain S. pastorianus W34/70 (Sp.W34/70) was used as a fermentation positive control. Similarly, micro-fermentations at $12{ }^{\circ} \mathrm{C}$ followed the same procedure. 


\subsection{Ammonium and Amino Acid Analysis}

Ammonium and Amino acid consumption was evaluated at different time-points during the fermentation process. For this, a $100 \mathrm{~mm}$ cannula was inserted into the rubber stopper to perform periodical sampling. Samples were obtained at 24, 48, and $168 \mathrm{~h}$ by extracting 0.5 to $1 \mathrm{~mL}$ of fermented beer wort. Each sample was centrifuged at 13,000 rpm for $5 \mathrm{~min}$, and the supernatant was recovered and stored at $-20{ }^{\circ} \mathrm{C}$. Fermented wort was processed following the protocol described by Gomez-Alonzo et al. 2007. Briefly, $120 \mu \mathrm{L}$ of the sample was incubated with $20 \mu \mathrm{L}$ of diethylethoxymethylen-emalonate (DEEMM, SIGMA) for $24 \mathrm{~h}$ at room temperature in a solution containing $580 \mu \mathrm{L}$ of a borate buffer $(\mathrm{pH}=9)$ and $250 \mu \mathrm{L}$ of absolute methanol (Fisher Chemical). The sample was heated at $70{ }^{\circ} \mathrm{C}$ for $2 \mathrm{~h}$ to allow the complete degradation of excess DEEMM and reagent byproducts. After the derivatization reaction, $20 \mu \mathrm{L}$ of the processed samples were analyzed by High-Performance Liquid Chromatography (HPLC, Shimadzu) with a C18-HL column $(250 \mathrm{~mm} \times 4.6 \mathrm{~mm})$, a binary gradient (phase A: phase B:), and a flow rate of $0.9 \mathrm{~mL} / \mathrm{min}$. For detection, a photodiode array detector (Shimadzu, Kokyo, Japan) set at 270, and 280 nm was used. The different compounds were identified according to the retention time and UV-vis spectral characteristics of the derivatives of the corresponding standards and were quantified using the internal standard's method.

\subsection{HS-SPME-GC-MS Analysis}

Analysis of the production of all VCs was carried out by the combination of four analytical procedures: headspace, solid-phase microextraction, gas chromatography, and mass spectrometry (HS-SPME-GC-MS, Thermo Scientifics, Whaltam, MA, USA). A headspace vial was loaded with $2 \mathrm{~mL}$ of sample and equilibrated at extraction temperature $\left(60{ }^{\circ} \mathrm{C}\right)$ for $30 \mathrm{~min}$. Then, a 50/30 $\mu \mathrm{m}$ divinylbenzene/carboxenpolydimethylsiloxane fiber (DVB/Car/PDMS; Supelco, Bellefonte, PA, USA) was introduced within the headspace vial in order to extract the volatiles, through a silicon septum for $30 \mathrm{~min}$. Targeted volatiles loaded in the fiber were analyzed by using a GC-MS (Thermo Scientifics Trace GC Ultra, equipped with Thermo Scientifics ISQ quadrupole mass spectrometer and autosampler Thermo Scientifics Triplus) and GC-MS/MS (Thermo Scientifics Trace 1300 GC, equipped with Thermo Scientifics TSQ Triple quadrupole mass spectrometer and autosampler Thermo Scientifics Triplus RHS) in full-scan mode. The desorption of the fiber was carried out (splitless mode) at $250{ }^{\circ} \mathrm{C}$ for $5 \mathrm{~min}$ and cleaning at $270{ }^{\circ} \mathrm{C}$ for $15 \mathrm{~min}$. Helium was passed at a constant flow $(1.2 \mathrm{~mL} / \mathrm{min})$ for serving as a carrier gas. Mass spectrometry detection was performed under electron impact (EI) ionization at $70 \mathrm{eV}$ by operating in the full-scan acquisition mode in the $40-400 \mathrm{~m} / \mathrm{z}$ range. Ion source and transfer line temperature were maintained at $250{ }^{\circ} \mathrm{C}$, respectively. Potential emanations were analyzed using Xcalibur Software (Thermo Electron Corporation) matching mass spectra with those saved in the National Institute of Standards and Technology (NIST) MS Spectral Library 2014. Chromatographic peaks were considered "unknown" when their similarity index (SI) and reverse similarity index (RSI) were less than 850 and discarded in this identification process. These parameters refer to the degree at which the target spectrum matches the standard spectrum in the NIST Library (a value of 1000 indicates a perfect fit). Selected chromatographic peaks were checked with their respective chemical standards and Kovats indexes [26].

\subsection{Statistical Analyses}

All statistical analyses were performed using biological triplicates. One-way ANOVAs (Analysis of Variance) and Pearson non-parametric correlations ( $t$-Test) were performed using GraphPad Prism 8.01 for Windows, GraphPad Software, La Jolla, CA, USA, www.graphpad.com. The differences were considered statistically significant at $p$-values $<0.05$. A principal component analysis (PCA) was performed using R software [27], and the "prcomp" package stats 3.6.0 and plotted using the "ggbiplot" package. Temperature data for the correlation analyses was obtained from the Center of Climate 
and Resilience Research (http://www.cr2.cl/datos-de-temperatura/). The data obtained correspond to measurements of daily average temperature recorded in 33 stations of the Chilean Meteorological Center and in 196 stations of the General Direction for Water during 2018.

\section{Results}

\subsection{Differences in Fermentation Capacity Across S. eubayanus Isolates}

To evaluate the fermentative capacity and differences in kinetic profiles of S. eubayanus strains when brewing wort, we performed a micro-fermentation assay using 20 strains obtained from different sites in central and Chilean Patagonia [22] (Figure 1a, Table S1). For this, strains were inoculated in beer wort, and $\mathrm{CO}_{2}$ release was measured for 14 days (see Methods). The strains exhibiting the greatest levels of $\mathrm{CO}_{2}$ release at the end of the fermentation were CL1107.1 (Nahuelbuta National Park, $p$-value $=0.422$, ANOVA) and CL600.1 (Antillanca National Park, $p$-value $=0.294$, ANOVA), neither of them exhibited significant differences when compared to the commercial strain (Sp.W34/70) (Figure 1b). Interestingly, these two strains were obtained from different sampling sites (central Chile and northern Chilean Patagonia, Figure 1a, and Figure S1). On the other hand, strains with the lowest fermentative capacity were CL1002.1 (Torres del Paine National Park, $p$-value $<0.0001$, ANOVA), CL814.1 (Magallanes National Reserve, $p$-value < 0.0001, ANOVA), CL815.1 (Magallanes National Park, $p$-value < 0.0001), CL606.1 (Vicente Pérez Rosales National Park, $p$-value < 0.0001, ANOVA), and CL801.1 (Karukinka Natural Park, $p$-value < 0.0001, ANOVA), all of them from the central and southern Chilean Patagonia sampling sites (Figure 1a,b and Figure S1).

To determine whether fermentation performance correlated with climate and/or geographic conditions, we performed a correlation test between $\mathrm{CO}_{2}$ release and: i) latitude and ii) average yearly temperature. We found a significant correlation for both parameters: latitude (Pearson $\mathrm{r}=-0.58$, $p$-value $<0.001, t$-Test) and average yearly temperature per isolation locality (Pearson $r=0.59$, $p$-value $<0.001, t$-Test) vs. $\mathrm{CO}_{2}$ loss (Figure 1c,d). The observed differences could correlate with fermentation capacity and $\mathrm{CO}_{2}$ release, indicating different fermentative potentials between strains depending on their geographic origin.

\subsection{Volatile Compound Production in S. eubayanus Isolates}

To characterize the VC production profiles of the S. eubayanus strains, we analyzed the fermented wort by HS-SPME-GC-MS VCs and identified VCs whose identity is unknown, rather than using internal standards for commonly known compounds. To attain this, we selected 10 strains based on the two following criteria: (i) One representative isolate from each sampling site and (ii) significantly different fermentative capacities $\left(\mathrm{CO}_{2}\right.$ release levels) between strains to maximize the genetic and phenotypic diversity. Therefore, we selected strains with high fermentative capacity (CL1107.1 and CL450.1), mid-fermentation capacity (CL711.2, CL216.1, CL905.1, CL602.1, and CL812.1), and low fermentative capacity (CL606.1, CL1002.1, and CL814.1) (Figure 1b). HS-SPME-GC-MS analyses using the 10 selected strains, together with the Sp.W34/70 lager control, allowed the identification of 55 different compounds in all fermented wort (Figure 2a, Table S2). Out of these compounds, 52 were found in S. eubayanus strains and 22 were found in the lager strain (Sp.W34/70) (Figure 2a). Interestingly, 32 compounds were exclusive to S. eubayanus and were not detected in Sp.W34/70. In comparison, only three compounds (ethyl hexanoate, ethyl heptanoate, and ethyl dihydrocinnamate) were found solely in the commercial strain Sp.W34/70, resulting in 19 compounds common to both species (Figure 2a, Table S2). These results demonstrate that all compounds (except ethyl hexanoate, ethyl heptanoate, and ethyl dihydrocinnamate) generated by the lager strain are found in at least one wild isolate. Among all the analyzed compounds, esters represent the main fraction of the VCs identified (26 in wild S. eubayanus and 15 in Sp.W34/70) (Figure 2b,c), where 14 compounds were found in common across both species (Figure 2b). Interestingly, of the whole set of VCs identified, only a single higher alcohol, phenethyl alcohol, was detected by HS-SPME-GC-MS. In contrast, no phenolic compounds 
were identified in the lager strain. However, in wild S. eubayanus, we discovered two different phenolic compounds: 4-vinylguaiacol (4-VG), which was found in all strains and 2,4-Di-tert-butylphenol, which was only identified in CL1002.1 and CL602.1. A negative and significant correlation was found between the number of VCs produced at the end of the fermentation process and fermentation capacity (Pearson $r=-0.35, p$-value $<0.05$, $t$-Test, Pearson Correlation). In this context, strains with a higher fermentative capacity produced a lower number of (identified) compounds, suggesting that the production of a wider number of VCs is not directly related to high fermentation capacity (Figure 2d).
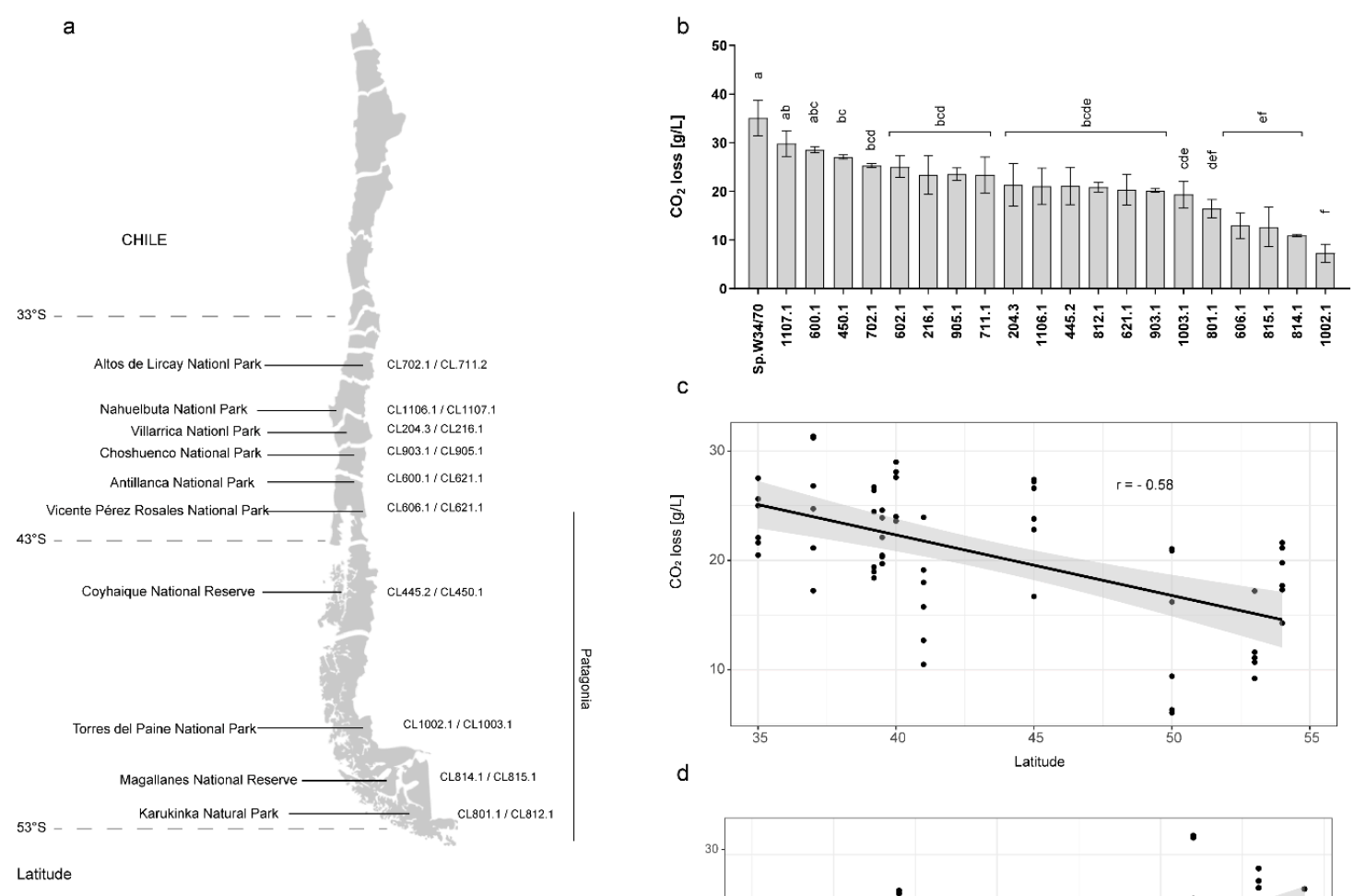

d

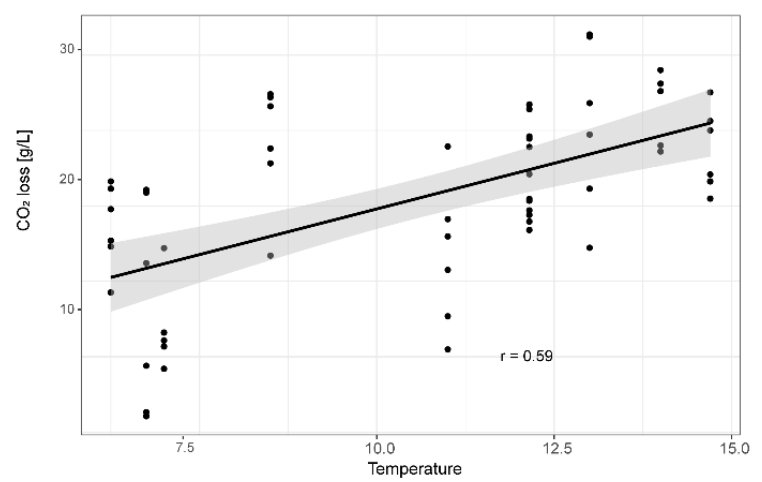

Figure 1. Saccharomyces eubayanus fermentation performance in lager wort. (a) The geographical location of the sampling sites and the strain codes from each locality. (b) Total $\mathrm{CO}_{2} \operatorname{loss}[\mathrm{g} / \mathrm{L}]$ in fermentations carried out by S. eubayanus strains. Lager strain S. pastorianus W34/70 was used as a fermentation control. Different letters reflect statistically significant differences between strains with a $p$-value $<0.05$, one-way ANOVA. (c) Latitude and (d) annual average temperature at the isolation site of each strain vs. $\mathrm{CO}_{2}$ loss (Pearson Correlation). Each dot represents a fermentation replicate. Three biological replicates were analyzed per strain. 
a

\section{S. eubayanus}

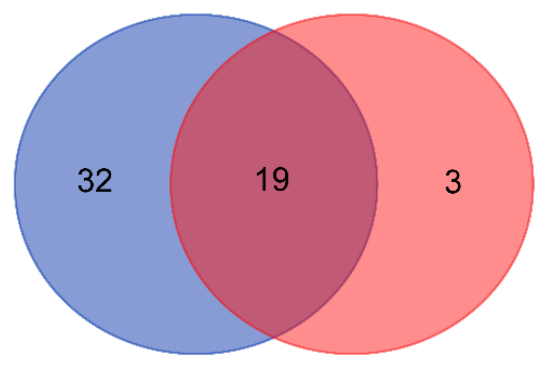

Sp.W34/70

\section{S. eubayanus}

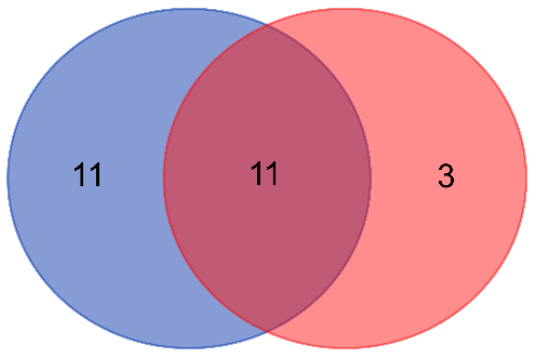

Sp.W34/70
C

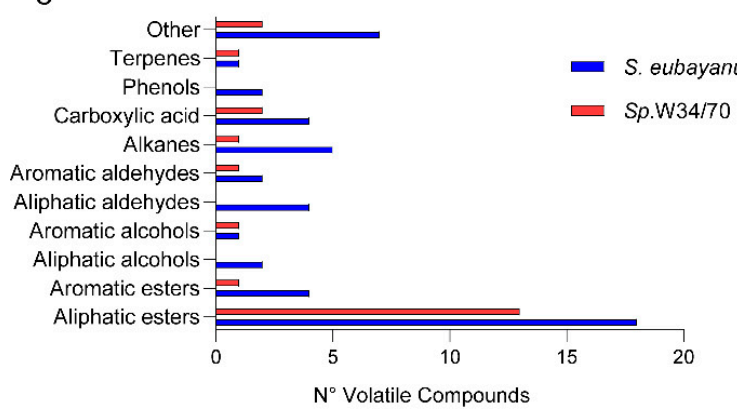

d

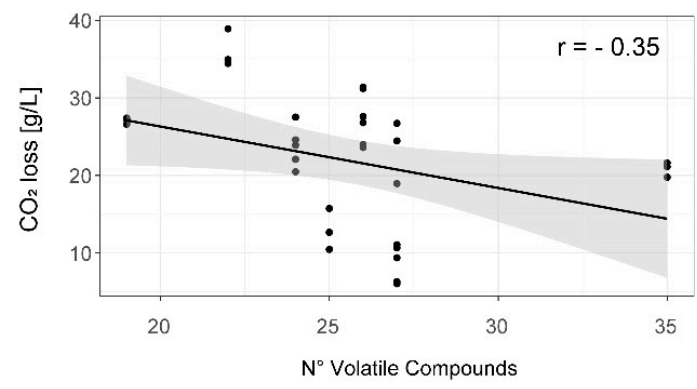

Figure 2. Volatile compounds identified in lager beer micro-fermentations using wild S. eubayanus and the Sp.W34/70 strain. (a) Total VCs identified in beer wort fermented by wild Chilean S. eubayanus (Blue) strains and S. pastorianus W34/70 (Red). (b) Total esters identified in beer wort fermented with wild Chilean S. eubayanus (Blue) strains and S. pastorianus W34/70 (Red). (c). Main chemical groups detected in fermented beer wort. (d) Correlation between the number of VCs produced and fermentative capacity. Each point depicts a biological replicate.

\subsection{Main Volatile Compounds Identified in Fermented Wort}

To improve our comparative analysis of VC production profiles across strains, we selected compounds comprising the highest relative amounts, representing at least $45 \%$ of the total VC area detected and that were identified in at least five $S$. eubayanus strains (Table 1, Figure 3). In this way, we selected 12 compounds, most of them aliphatic esters. Of these, ethyl octanoate (aliphatic ester), ethyl hexadecanoate (aliphatic ester), phenethyl alcohol (aromatic alcohol), and n-decanoic acid (carboxylic acid) were found in all strains in similar relative amounts (Figure 3). On the other hand, among the aliphatic esters detected by HS-SPME-GC-MS, ethyl decanoate was the most abundant VC, especially in the CL1002.1 isolate from Torres del Paine National Park (3300 $\pm 879.8, p$-value $<0.05$, ANOVA) (Table 1). Other compounds, such as isoamyl decanoate, phenethyl acetate (aromatic ester), phenethyl decanoate (aromatic ester), and octanoic acid (carboxylic acid) (Figure 3), were exclusively detected in a subset of strains (Table 1). Within the detected off-flavors, 4-VG (phenols) exhibited one of the highest area contributions to the profiles of the strains, being identified at similar levels in all strains ( $p$-value > 0.05, ANOVA, Figure 3), except for CL602.1 ( $p$-value < 0.05, ANOVA), exhibiting a lower detected relative amount compared to the other strains $(98.8 \pm 11.4)$. 
Table 1. Main Volatile Compounds detected in S. eubayanus.

\begin{tabular}{|c|c|c|c|c|c|c|c|c|c|c|c|c|}
\hline \multirow[b]{3}{*}{ Chemical Group } & \multirow[b]{3}{*}{ Compound Name } & \multirow[b]{3}{*}{ RI } & \multicolumn{10}{|c|}{ Relative Amount $\left(\times 10^{6}\right)$ and SEM } \\
\hline & & & \multicolumn{10}{|c|}{ Strains } \\
\hline & & & CL1107.1 & CL1002.1 & CL905.1 & CL814.1 & CL812.1 & CL711.2 & CL606.1 & CL602.1 & CL450.1 & CL216.1 \\
\hline \multirow[t]{6}{*}{ Aliphatic esters } & Ethyl octanoate & 1192.64 & $506.1 \pm 91.8$ & $1400 \pm 226.4$ & $483.1 \pm 250.2$ & $1300 \pm 1100$ & $446.4 \pm 144$ & $276.7 \pm 31.7$ & $812.9 \pm 123.5$ & $228.8 \pm 76$ & $230.2 \pm 73.7$ & $819.5 \pm 151.7$ \\
\hline & Ethyl decanoate & 1391.77 & $1400 \pm 522.4$ & $3300 \pm 879.8$ & $1700 \pm 734.6$ & $1500 \pm 1200$ & $1100 \pm 118.7$ & $870.3 \pm 219.4$ & $2400 \pm 635.3$ & $141.7 \pm 38.3$ & $362 \pm 152.8$ & $802.2 \pm 253.5$ \\
\hline & Ethyl dodecanoate & 1443.83 & $793.6 \pm 226$ & $1000 \pm 289.6$ & $1600 \pm 357.4$ & $164.5 \pm 96.9$ & $325.8 \pm 11.7$ & $868.5 \pm 260.4$ & $872.2 \pm 73.8$ & $123.7 \pm 17$ & $335.3 \pm 125.3$ & $186 \pm 30.2$ \\
\hline & Isoamyl decanoate & 1590.63 & $99.7 \pm 25.7$ & $180.5 \pm 43.5$ & $102.1 \pm 28.9$ & $50.8 \pm 30$ & $42.4 \pm 2.1$ & $74.9 \pm 8.1$ & $129.4 \pm 29.3$ & $\mathrm{~N} / \mathrm{D}$ & $\mathrm{N} / \mathrm{D}$ & $33.5 \pm 10.5$ \\
\hline & Ethyl tetradecanoate & 1790.87 & $160.3 \pm 50.9$ & $89.8 \pm 28.2$ & $228.2 \pm 38.9$ & $23.7 \pm 8$ & $54.3 \pm 10.5$ & $166 \pm 50$ & $115.2 \pm 21.6$ & $49.7 \pm 6.8$ & $104.5 \pm 38.3$ & $\mathrm{~N} / \mathrm{D}$ \\
\hline & Ethyl hexadecanoate & 1991.92 & $552 \pm 241.4$ & $169 \pm 53.7$ & $666 \pm 179.7$ & $53.4 \pm 7.4$ & $161.3 \pm 34.4$ & $363 \pm 85.2$ & $242.5 \pm 37.5$ & $229.4 \pm 65.1$ & $274.3 \pm 115.2$ & $136.9 \pm 20$ \\
\hline \multirow[t]{2}{*}{ Aromatic esters } & Phenethyl acetate & 1250.12 & $490.8 \pm 79.1$ & $189.8 \pm 17$ & $522.4 \pm 233.1$ & $212.9 \pm 172.2$ & $232.1 \pm 78.9$ & $501.7 \pm 95.5$ & $360.2 \pm 84.7$ & N/D & $\mathrm{N} / \mathrm{D}$ & $312.6 \pm 79.2$ \\
\hline & Phenethyl decanoate & 2062.65 & $149.5 \pm 32.8$ & $369.7 \pm 62.8$ & $\mathrm{~N} / \mathrm{D}$ & $\mathrm{N} / \mathrm{D}$ & $27.7 \pm 5.3$ & $123.7 \pm 40.7$ & $170.8 \pm 25.3$ & N/D & $\mathrm{N} / \mathrm{D}$ & $\mathrm{N} / \mathrm{D}$ \\
\hline Aromatic alcohol & Phenethyl Alcohol & 1116.19 & $2900 \pm 1600$ & $1500 \pm 409.3$ & $3800 \pm 971.5$ & $1800 \pm 1400$ & $2500 \pm 992.4$ & $3700 \pm 1100$ & $2000 \pm 627$ & $2900 \pm 805$ & $3200 \pm 565.2$ & $3200 \pm 1000$ \\
\hline \multirow[t]{2}{*}{ Carboxylic acid } & Octanoic acid & 1171.39 & $483 \pm 91.8$ & $\mathrm{~N} / \mathrm{D}$ & $633.5 \pm 101.3$ & $\mathrm{~N} / \mathrm{D}$ & $22.9 \pm 17.4$ & $\mathrm{~N} / \mathrm{D}$ & & $12.5 \pm 2.4$ & $\mathrm{~N} / \mathrm{D}$ & $39 \pm 13.1$ \\
\hline & n-Decanoic acid & 1360.8 & $200 \pm 59$ & $198 \pm 8.8$ & $127.5 \pm 11$ & $93.3 \pm 43.8$ & $93.4 \pm 7.8$ & $163.3 \pm 25.6$ & $158.3 \pm 16.1$ & & $120.4 \pm 28.9$ & $81.9 \pm 25.6$ \\
\hline Phenols & 4-vinylguaiacol & 1317.45 & $281.4 \pm 11.2$ & $310.9 \pm 22.3$ & $238.7 \pm 39.4$ & $250.1 \pm 167.4$ & $258.7 \pm 53.9$ & $287.5 \pm 21.8$ & $292.7 \pm 17.6$ & $98.8 \pm 11.4$ & $118.1 \pm 15$ & $284.1 \pm 14.5$ \\
\hline
\end{tabular}

Compounds detected in S. eubayanus fermentation by headspace solid-phase microextraction followed by gas chromatography-mass spectrometry (HS-SPME-GC-MS). SEM: standard error of the mean; CAS: Chemical Abstracts Service; N/D: Not Detected; RI: Kovats retention indices. 

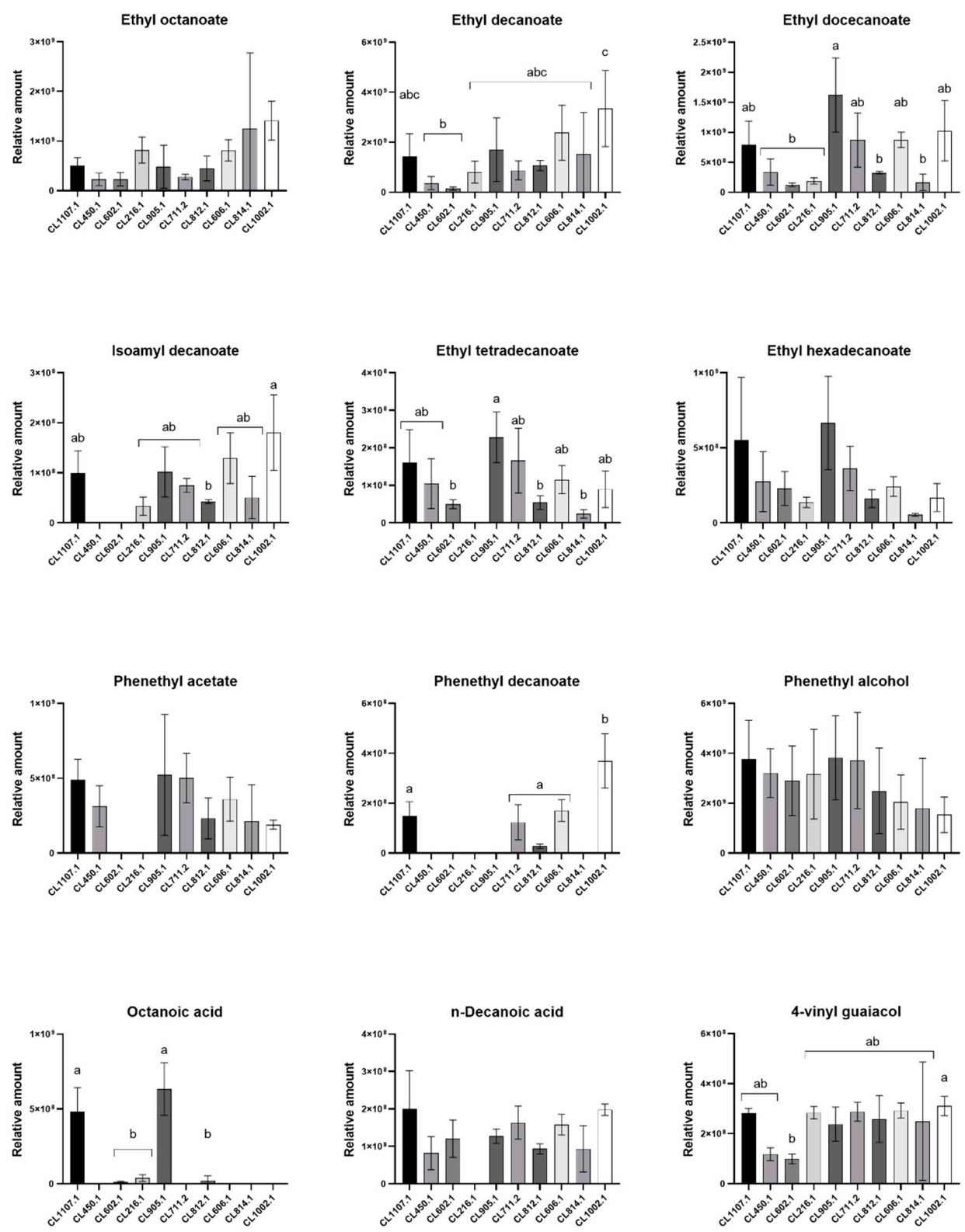

Figure 3. Relative amounts of the main volatile compounds in fermented wort at $12{ }^{\circ} \mathrm{C}$. The strains are distributed according to their fermentative capacity from high to low levels (left to right). Different letters reflect statistically significant differences between strains with a $p$-value $<0.001$, one-way ANOVA. No-letters strains do not show statistically significant differences.

To reduce the dimensionality of our dataset and interpret the profile of VC production for each strain, we performed a global principal component analysis (PCA) using the 12 selected VCs (Figure 4). The two first component explained $46.6 \%$ and $37 \%$ of the observed variation, respectively, allowing us to classify the S. eubayanus strain profiles in four groups: (Q1) CL450.1 and CL602.1, (Q2) CL812.1, CL216.1 and CL814.1, (Q3) CL905.1, CL1107.1 and CL711.2, and (Q4) CL606.1 and CL1002.1. Interestingly, strains in Q2 produced higher amounts of VCs, such as phenethyl alcohol and ethyl tetradecanoate, while those in Q3 showed higher areas for isoamyl decanoate and ethyl decanoate. This analysis suggests that strains with similar aromatic profiles do not have a common geographical or genetic origin, with isolates from central and southern Chile being found in all groups. Similarly, except for phenethyl alcohol ( $\mathrm{r}=-0.75, p$-value $<0.05, t$-Test, Pearson Correlation), no significant correlation was found ( $p$-value $>0.05, t$-Test, Pearson Correlation) when relating latitude (origin of the strains) with 
the relative amount of the primary VC produced (Figure S2). Altogether, our results show the broad spectrum of VC profiles in S. eubayanus strains from different sites, and highlight the organoleptic potential for innovation in the brewing industry of this newly discovered yeast.

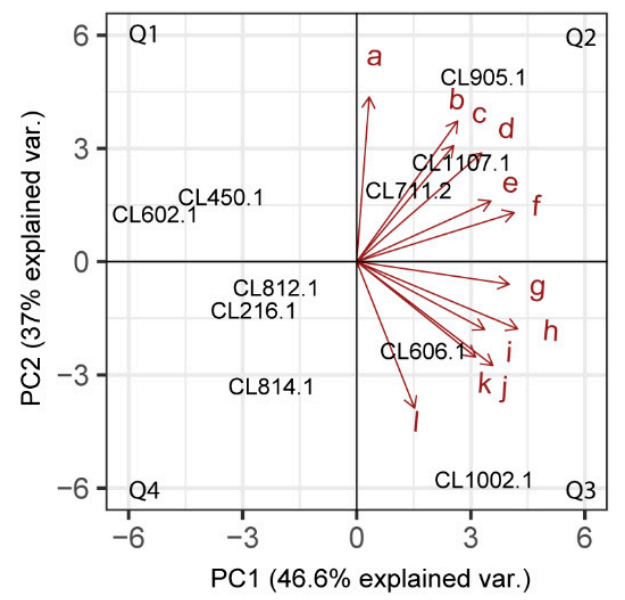

Figure 4. Principal Component Analysis of VC production across S. eubayanus strains. Distribution of the selected strains based on the leading VCs produced. a: Phenethyl Alcohol, b: Ethyl hexadecanoate, c: Octanoic acid, d: Ethyl tetradecanoate, e: Phenethyl acetate, f: Ethyl dodecanoate, g: n-Decanoic acid, h: Isoamyl decanoate, i: 4-vinyl guaiacol, j: Ethyl decanoate, k: Phenethyl decanoate, l: Ethyl octanoate. The strains were distributed in four quadrants, Q1: First group. Q2: Second group. Q3: Third group. Q4: Fourth group.

\subsection{Fermentation Temperature Impacts the Volatile Compound Profile in S. eubayanus Strains}

Depending on the strain and fermentation temperature, producers can fine-tune the aromatic profiles of beverages. We compared the temperature dependence of S. eubayanus strains and their impact on the production of VCs in brewing wort at the end of fermentation. For this, we selected two strains (CL905.1 and CL602.1) with (i) similar fermentative capacity (Figure 1b) and (ii) different aromatic profiles and located in different quadrants in the PCA (Figure 4). In this way, we performed new fermentation batches at $12{ }^{\circ} \mathrm{C}$ and $20^{\circ} \mathrm{C}$ and identify the VCs produced at both temperatures using HS-SPME-GC-MS. Fermentative profiles were similar between strains at $20^{\circ} \mathrm{C}$ and did not show statistically significant differences for fermentation $\mathrm{CO}_{2}$ release. At $12{ }^{\circ} \mathrm{C}$, the strains show statistically significant differences for fermentation $\mathrm{CO}_{2}$ release with a $p$-value $<0.001$, ANOVA (Figure S3). We found that VC profiles differed in a strain- and temperature-dependent manner. Notably, at $12{ }^{\circ} \mathrm{C}$, the two isolates produced 16 compounds in common, rising to 20 when fermentation was run at $20^{\circ} \mathrm{C}$ (Table S3). In strain CL905.1, we identified 23 and 32 compounds at $12{ }^{\circ} \mathrm{C}$ and $20^{\circ} \mathrm{C}$, respectively, while the opposite was observed in CL602.1, where we identified 24 and 21 VCs at $12{ }^{\circ} \mathrm{C}$ and $20^{\circ} \mathrm{C}$, respectively. In the case of CL602.1, the main chemical group affected by temperature was the aliphatic esters, while in CL905.1, the main chemical groups with more compounds detected at higher temperature were aliphatic esters (1-hexanol, 2-ethyl, propanoic acid, 2-methyl,3-hydroxy-2,2,4-trimethylpentyl ester and ethyl 9-hexadecanoate), aliphatic alcohols (linalool, 1-octanol and 1-decanol), aromatic aldehydes (benzaldehyde, benzeneacetaldehyde and benzaldehyde, 4-methyl), and other compounds (1,1,3-trimethyl-3-phenylindane) (Table S3). These results demonstrate that fermentation temperature differentially modulates the total number of VCs depending on the strain and genetic background, likely impacting the aromatic profiles of the beers produced (Table 2, Table S3). 
Table 2. Main Volatile Compounds detected in CL905.1 and CL602.1.

\begin{tabular}{|c|c|c|c|c|c|c|}
\hline & & & \multicolumn{4}{|c|}{ Relative Abundance $\left(\times 10^{6}\right)$ and SEM } \\
\hline & & & \multicolumn{4}{|c|}{ Strain } \\
\hline & & & CL905.1 & & CL602.1 & \\
\hline Chemical Group & Compound & RI & $12{ }^{\circ} \mathrm{C}$ & $20^{\circ} \mathrm{C}$ & $12{ }^{\circ} \mathrm{C}$ & $20^{\circ} \mathrm{C}$ \\
\hline \multirow[t]{6}{*}{ Aliphatic esters } & Ethyl octanoate & 1192.63881 & $483.1 \pm 250.2$ & $1566.67 \pm 251.66$ & $228.8 \pm 76$ & $1566.67 \pm 120.19$ \\
\hline & Ethyl 9-decenoate & 1384.56268 & $448.5 \pm 165.1$ & $622.93 \pm 232.23$ & $137.5 \pm 63.5$ & $622.93 \pm 116.55$ \\
\hline & Ethyl decanoate & 1391.77014 & $1700 \pm 734.6$ & $3666.67 \pm 1011.60$ & $141.7 \pm 38.3$ & $3666.67 \pm 409.61$ \\
\hline & Isoamyl decanoate & 1644.71354 & $102.1 \pm 28.9$ & $162.40 \pm 44.51$ & $\mathrm{~N} / \mathrm{D}$ & $162.40 \pm 21.72$ \\
\hline & Ethyl tetradecanoate & 1786.82537 & $228.2 \pm 38.9$ & $267.33 \pm 52.60$ & $49.7 \pm 6.8$ & $267.33 \pm 23.47$ \\
\hline & Ethyl hexadecanoate & 1991.92208 & $666 \pm 179.7$ & $553.43 \pm 59.25$ & $\mathrm{~N} / \mathrm{D}$ & $553.43 \pm 48.51$ \\
\hline Aromatic esters & Phenethyl acetate & 1250.12471 & $522.4 \pm 233.1$ & $687.80 \pm 328.51$ & $\mathrm{~N} / \mathrm{D}$ & $687.80 \pm 189.00$ \\
\hline Aromatic alcohols & Phenethyl Alcohol & 1116.18753 & $3800 \pm 971.5$ & $8600.00 \pm 346.41$ & $2900 \pm 805$ & $8600.00 \pm 851.14$ \\
\hline Aromatic aldehydes & Benzaldehyde, 4-methyl & 1083.5138 & $\mathrm{~N} / \mathrm{D}$ & $170.50 \pm 58.41$ & $42.1 \pm 6$ & $170.50 \pm 21.10$ \\
\hline \multirow[t]{2}{*}{ Carboxylic acids } & Octanoic acid & 1171.38687 & $633.5 \pm 101.3$ & $\mathrm{~N} / \mathrm{D}$ & $12.5 \pm 2.4$ & $131.80 \pm 13.44$ \\
\hline & Dodecanoic acid & 1556.73878 & $38.3 \pm 3.4$ & $1866.67 \pm 404.15$ & $\mathrm{~N} / \mathrm{D}$ & $1866.67 \pm 135.36$ \\
\hline Phenols & 4-vinylguaiacol & 1317.44761 & $238.7 \pm 39.4$ & $308.03 \pm 76.01$ & $98.8 \pm 11.4$ & $290.93 \pm 38.64$ \\
\hline
\end{tabular}

Compounds detected in S. eubayanus fermentation by HS-SPME-GC-MS. SEM: standard error of the mean; CAS: Chemical Abstracts Service; N/D: Not detected: RI: Kovats retention indices. 
We next selected the compounds with the highest area percentage (representing approximately $65 \%$ of the area of the whole peak) in CL905.1 and CL602.1 strains (Figure 5, Table 2). In this way, we identified 12 main compounds at $12{ }^{\circ} \mathrm{C}$ and $20^{\circ} \mathrm{C}$, for which relative areas were compared between both strains. As previously mentioned, not only the number of VCs changed with temperature, but we also found differences in the relative amount produced depending on the fermentation temperature. For example, ethyl octanoate (aliphatic ester) and phenethyl alcohol (aromatic alcohol, higher alcohol) (Figure 5, Table 2) significantly increased at $20^{\circ} \mathrm{C}$ ( $p$-value $>0.001$, ANOVA), independently of the strain. On the other hand, higher levels in the relative amount of 4 -VG at $20^{\circ} \mathrm{C}$ compared to $12{ }^{\circ} \mathrm{C}$ was only observed in CL602.1 ( $p$-value > 0.001, ANOVA) and not in CL905.1 (Figure 5). Similarly, other ester compounds significantly increased with temperature solely in CL602.1, such as: ethyl 9-decanoate, ethyl decanoate, isoamyl decanoate, and phenethyl acetate ( $p$-value $>0.001$, ANOVA). Depending on the strain, a higher fermentation temperature allowed us to find novel compounds undetected at $12{ }^{\circ} \mathrm{C}$. For example, benzaldehyde 4-methyl (aromatic aldehyde) was exclusively detected in CL905.1 at $20^{\circ} \mathrm{C}$, but not at $12{ }^{\circ} \mathrm{C}$. In contrast, in CL602.1, this compound was detected at both temperatures ( $p$-value $<0.001$, ANOVA). These results demonstrate that fermentation temperature results in different profiles in both strains in terms of the number of compounds, but also in their relative amounts, representing a strain $\times$ temperature specific interaction.
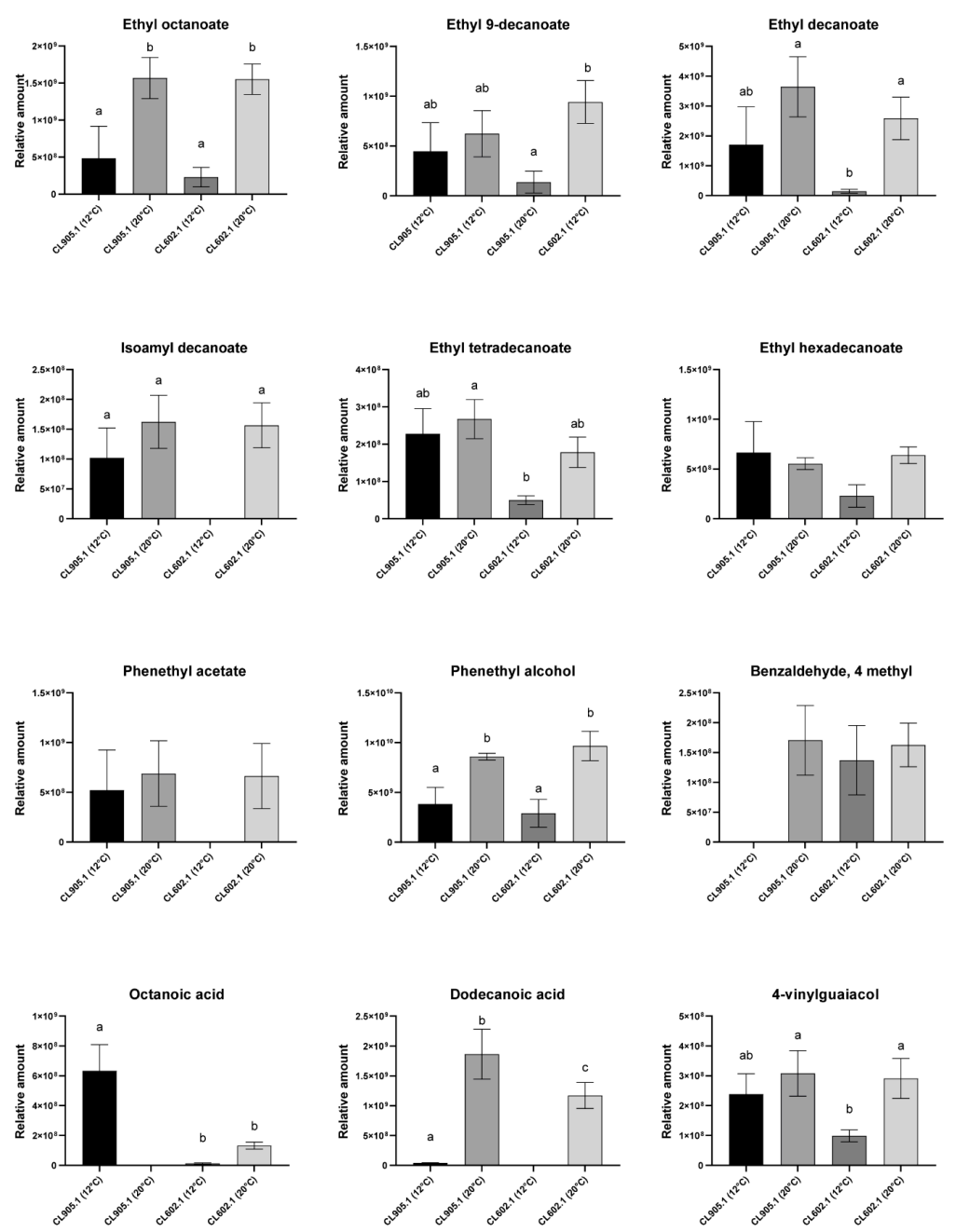

Figure 5. Relative amounts of main volatile compounds identified in fermented wort at 12 and $20^{\circ} \mathrm{C}$. CL905.1 (Choshuenco National Park) and CL602.1 (Antillanca National Park) were fermented at $12{ }^{\circ} \mathrm{C}$ and $20^{\circ} \mathrm{C}$, respectively. Different letters reflect statistically significant differences between strains with a $p$-value $<0.001$, one-way ANOVA. No-letters strains do not show statistically significant differences. 


\subsection{Nitrogen Consumption Differentially Impacts the Prodcution of Volatile Compounds}

The ability to assimilate different nitrogen sources in the brewing wort directly impacts the physiology of yeasts during the fermentation process. Simultaneously, the differential consumption of nitrogen sources could affect the aroma and flavor profiles of fermented wort [1,28-30]. In this context, to determine the nitrogen consumption profiles of the two strains (CL905.1 and CL602.1) at $12{ }^{\circ} \mathrm{C}$ and $20^{\circ} \mathrm{C}$ during fermentation, yeast assimilable nitrogen (YAN) consumption was measured by HPLC after 24, 48, and $168 \mathrm{~h}$ of fermentation (Figure 6). In the case of ammonium, that represents $29.02 \%$ (Table S4) of the overall YAN in the beer wort, $21.98 \% \pm 1.31 \%$ of all the available ammonium was consumed by $24 \mathrm{~h}$ at $20{ }^{\circ} \mathrm{C}$, while at $12{ }^{\circ} \mathrm{C}$, a similar fraction $(14.82 \% \pm 10.50 \%$, $p$-value $<0.001$, one-way ANOVA) was reached at $48 \mathrm{~h}$ (Figure 6a, Table S4). In this way, when we compared the effect of temperature over the consumption of ammonium in both strains, significant differences were observed only at $24 \mathrm{~h}$ ( $p$-value $<0.05$, ANOVA) (Figure $6 \mathrm{a}$ ), while at $168 \mathrm{~h}$, most of the ammonium was already consumed in both strains, suggesting a temperature dependent (and not strain dependent) nitrogen consumption rate.

a

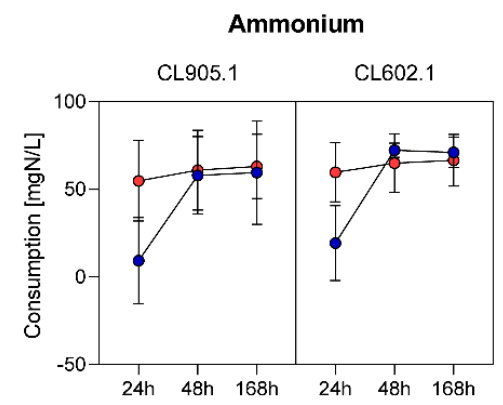

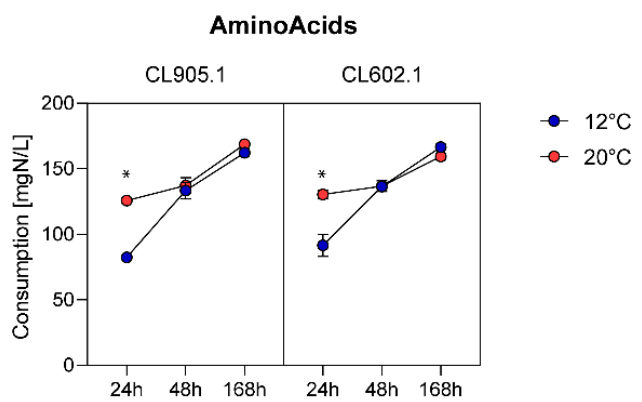

b
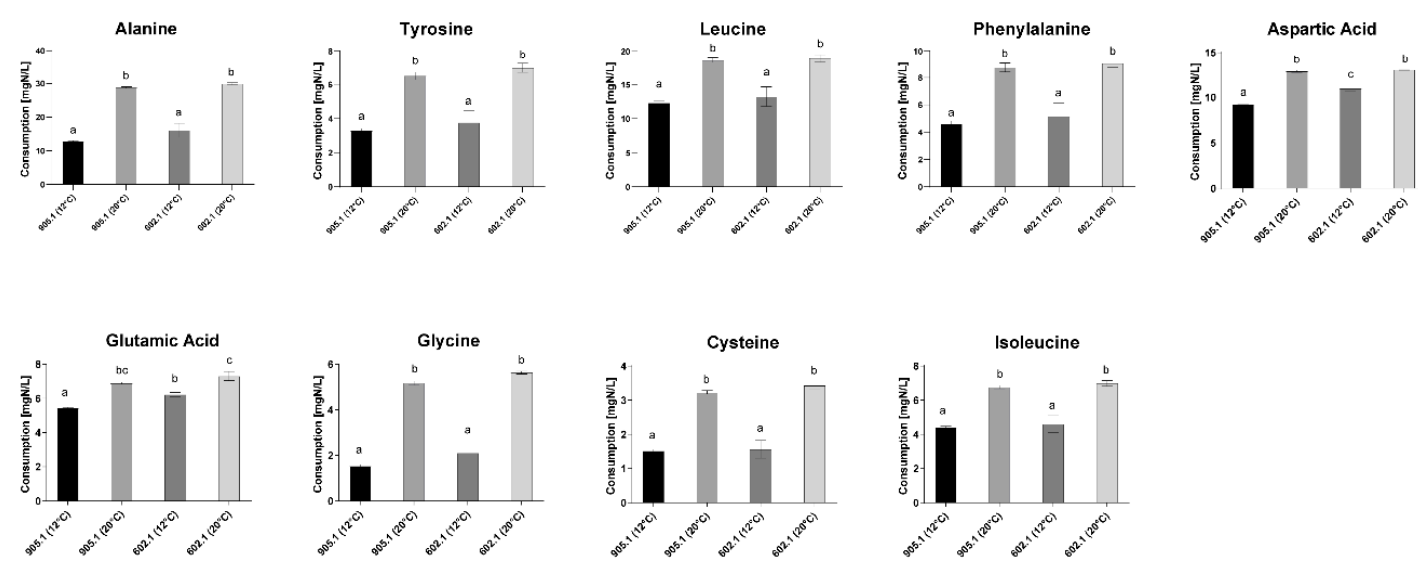

Figure 6. Differential yeast assimilable nitrogen (YAN) consumption in CL905.1 and CL602.1 strains at $12^{\circ} \mathrm{C}$ and $20^{\circ} \mathrm{C}$. (a) Ammonium and amino acid consumption kinetics at 24,48 , and $168 \mathrm{~h}$. Blue dots: $12{ }^{\circ} \mathrm{C}$ fermentation; Red dots: $20^{\circ} \mathrm{C}$ fermentation. $\left.{ }^{*}\right)$ depict significant differences between temperatures with a $p$-value $<0.001$, one-way ANOVA. (b) Main differences in amino Acid consumption between temperatures. Different letters depict significant differences between strains with a $p$-value $<0.05$, one-way ANOVA.

Subsequently, we analyzed the consumption of amino acids in wort. In this way, we found that their consumption rate was slower compared to ammonium, where both strains exhibited significant differences at $24 \mathrm{~h}$ between $12{ }^{\circ} \mathrm{C}$ and $20^{\circ} \mathrm{C}$ (Figure 6a, Table S4). Strain CL905.1 consumed $82.44 \pm 1.95 \mathrm{mg} \mathrm{N} / \mathrm{L}$ at $12{ }^{\circ} \mathrm{C}$, while a higher value was reached $(125.77 \pm 2.13 \mathrm{mg} \mathrm{N} / \mathrm{L}, p$-value $<0.001$, ANOVA) when the fermentation temperature was set to $20^{\circ} \mathrm{C}$. Similarly, CL602.1 showed an increase in amino acid consumption between $12{ }^{\circ} \mathrm{C}(91.56 \pm 8.41 \mathrm{mg} \mathrm{N} / \mathrm{L})$ and $20^{\circ} \mathrm{C}(130.36 \pm 3.28 \mathrm{mg} \mathrm{N} / \mathrm{L}$, 
$p$-value $<0.001$, ANOVA) (Table S4), demonstrating differential amino acid consumption depending solely on the fermentation temperature, but not on these genetic backgrounds. Of all the amino acids analyzed in this study (Table S5), solely glutamic acid and aspartic acid significantly differed at $12{ }^{\circ} \mathrm{C}$ (Figure $6 \mathrm{~b}$ ) ( $p$-value $<0.05$, ANOVA) between strains, while for the rest of the amino acids, the differences were due to an increase in fermentation temperature, independently of the strain (Figure 6b). Additionally, we determined that, for both strains, several amino acids, such as aspartic acid, glutamic acid, serine, and threonine, were rapidly consumed in the wort ( $>60 \%)$ at $24 \mathrm{~h}$, demonstrating the preference of S. eubayanus strains for these nitrogen sources (Figure 7, Table S5). On the other hand, amino acids such as histidine, glycine, tyrosine, and cysteine had lower consumption levels $(<30 \%)$ at $24 \mathrm{~h}$ (low preference) and were efficiently consumed (>80\%) only at $168 \mathrm{~h}$ (Table S7).

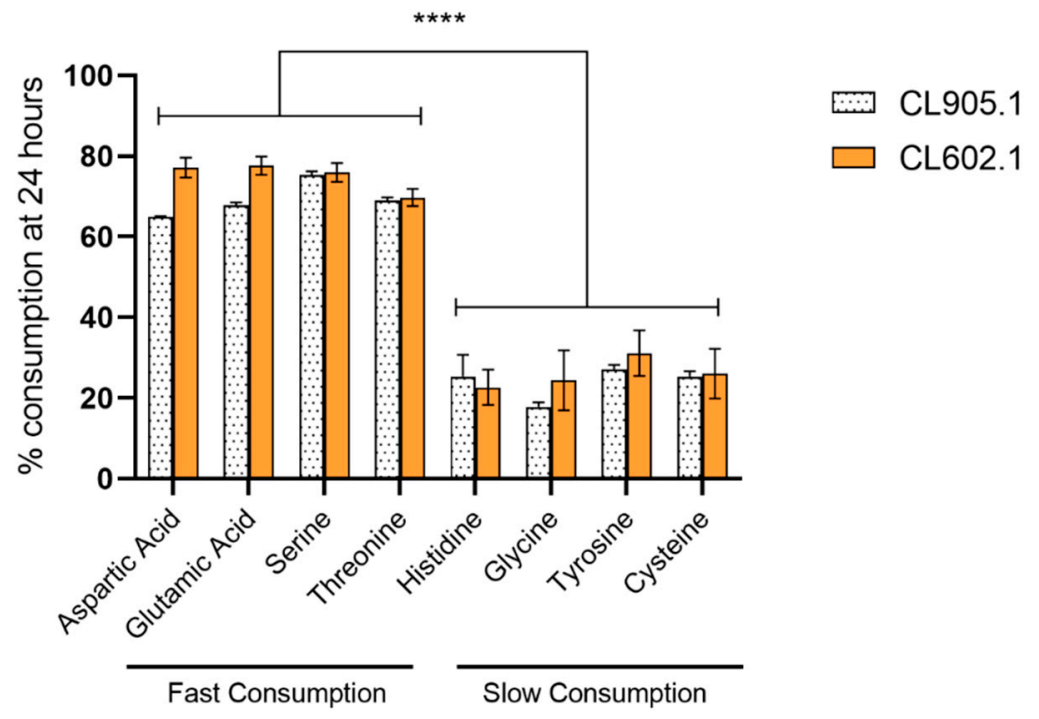

Figure 7. Preferred amino acid consumption in S. eubayanus strains at $24 \mathrm{~h}$. Gray: CL905.1; Orange: CL602.1. ${ }^{* * * *}$ ) depict significant differences between amino acids with a $p$-value $<0.001$, one-way ANOVA.

\section{Discussion}

Beer is a complex mixture of ingredients, brewed from raw materials including water, malt, hops, and yeast, that contains a broad range of different components that react and interact at all stages of the brewing process [2]. Yeasts employed in industrial fermentation processes can convert relatively high concentrations of sugars into ethanol, carbon dioxide, and a wide range of secondary metabolites [31], which impact in several ways the aromatic profile of beer. While these compounds are only produced at low concentrations, they are responsible for the complex aromas of fermented beverages. Currently, alternative yeast strains are being considered to provide new and innovative beers [32]. Under this scenario, and considering the recent market trends, bioprospecting research on pioneering wild yeast strains with the capacity to produce new beers is becoming an attractive field in food research. In this way, the recent finding of S. eubayanus in Patagonia is a crucial element for beer microbial innovation $[6,9,17,22]$. In this study, we analyzed the fermentation capacity and VC production of a genetically diverse set of Patagonian S. eubayanus strains from Chile, previously described by Nespolo et al. [22]. To our knowledge, this represents the first study that explores the landscape of VCs produced during beer fermentation in S. eubayanus using HS-SPME-GC-MS. The differences observed between these strains relate to those previously reported, where strains with higher stress tolerance developed a greater fermentative capacity than other strains [22,33]. Accordingly, the worldwide increase in beer consumption and the continuous growth of microbrewers highlight the need for the characterization of the aromatic profile of novel beers, requiring tools to evaluate beer quality and authenticity. In this context, the HS-SPME-GC-MS method, used in this 
analysis, has been reported as a fast and sensitive technique for the identification of VCs in both industrial and craft beers $[10,34]$. This technique develops reproducible data, with the improvement that avoids the injection of the standards, favoring several advantages, such as the time and cost of the analysis [10]. In HS-SPME (headspace solid-phase microextraction), analytes are extracted into a thin fused-silica fiber coated with the extracting phase by immersing it in the headspace of solid or liquid samples. Then, by GC-MS, compound identification is based on mass spectra matching with the standard NIST 08 MS library and on the comparison of retention indices (RI) sourced from the NIST Standard Reference Database MS Spectral Library 2014. The identification of the VCs by comparing the experimental mass spectra based on spectral similarity with those stored in the NIST MS library database, without chemical reference standards, should be regarded as putative compounds identifications (Level 2). Moreover, the determination of Kovats retention indices (RI) and their match with those available in previous literature [10,34] represents a useful tool for identification purposes, being independent of the operating conditions, except for the polarity of the used stationary phase. Furthermore, considering complex matrices as wort fermentation, which can contain hundreds of VCs to be analyzed, this analytical approach described above has the advantage that avoids the injection of the pure standards, favoring the time and cost of the analysis and the limitation that several standards are not commercially available.

In this study, we compared the VC production profile of two different yeast species, S. pastorianus (Sp.W34/70, commercial lager strain) and S. eubayanus (wild isolates from Chilean Patagonia) using HS-SPME-GC-MS. The main differences between S. eubayanus and S. pastorianus lie in the number (51 vs. 22) and the relative amounts of esters and phenols identified. These findings reflect the aromatic profile of the commercial strain, which likely lost the ability to produce a broad array of VCs due to a complex brewing domestication process. During this process, the fermentative capacity of the strain was prioritized over the production of complex aromatic profiles [35]. Esters were found in a higher proportion in the two yeast species analyzed in our study. These compounds are produced during the fermentation process and are usually characteristic of young beers [10]. Moreover, other compounds were identified, such as higher alcohols and phenols, of which the production is influenced by several factors, such as wort composition, fermentation parameters, and beer maturation state [34]. The presence of these compounds, together with volatile-esters, is responsible for contributing to the final beer flavor [1,8]. One of the most distinctive VCs produced by wild yeast is 4-VG [8]. The aroma and flavor descriptors used for this phenolic compound (identified in all S. eubayanus stains) are wide-ranging, and include stable, barnyard, horsey, leathery, smoky, spicy, clove, medicinal, and others (Dzialo M. et al. 2017; Lentz M. 2018), contributing significantly to the organoleptic profile. The role of phenols in the aromatic profile of the beer is questionable; in individual beer styles, such as Bavarian wheat beers and Belgian white beers (Lentz M. 2018), the phenolic flavors are desired and contribute to the style of the beer. However, the same VCs are perceived as undesirable in other fermented beverages and are commonly referred to as "phenolic off-flavors" (POF). Similar studies using other S. eubayanus strains [36], indicated that this species produces higher levels of esters, phenols, and higher alcohols in fermentations at low temperatures $\left(15^{\circ} \mathrm{C}\right)$, compared to $S p . \mathrm{W} 34 / 70$. Indeed, our results followed the same trend, as we detected an additional set of VCs previously uncharacterized in lager beers. In this context, considering the great and novel diversity of VCs produced, the S. eubayanus strains considered in our study show an innovative potential for alternative beer production.

The volatile fraction of beer includes over 800 different compounds, but only several dozen of these are considered flavor active [37]. In this context, we selected compounds that could be relevant to discriminate the set of S. eubayanus strains considered in our study and performed a PCA. When analyzing the distribution of the isolates, according to their aromatic profile, we observed a random distribution of the $S$. eubayanus strains. There are no strains grouped by fermentation capacity or geographic isolation zone. By dividing the PCA into four quadrants (Q1-Q4), it is remarkable that strains with similar fermentative profiles are distributed in opposite quadrants. Given this, the quantity and variety of the VCs produced by S. eubayanus isolates seem to be strain-specific traits, and reflect the 
great genetic diversity present in this species, as reported previously $[19,22]$. In this context, the genetic diversity and the different VCs identified in S. eubayanus resemble those described for S. cerevisiae, rather than S. pastorianus, likely determined by the genetic diversity of the species. S. eubayanus is not the sole species to produce large amounts of volatile esters. For example, S. cerevisiae strain Safale S-04 (Belgium) produces a wide range of these compounds, such as: ethyl acetate, isoamyl acetate, phenethyl acetate, ethyl decanoate, ethyl hexanoate, and ethyl octanoate [38,39], responsible for giving the fermented wort a fruity profile and in some cases a mixture with solvent aromas [7]. These profiles are attractive in the worldwide beer market, and the development of lager beers with fruity aromatic profiles fermented at low temperatures could likely be of interest in the global beer industry.

The parameters that affect the response of yeasts during the biosynthesis of aromatic compounds are diverse [7]. The production of active aromatic compounds is directly related to the yeast strain used in fermentation [1], as the genome of each strain is unique and will ultimately impact the final aroma profile of the beverage [40]. This is very well reported in S. cerevisiae [12,41-43], while in S. eubayanus, only a handful of studies have evaluated the aromatic profile in beer $[6,23,36]$. Other relevant parameters reported are wort composition, oxygen [44], yeast assimilable nitrogen (YAN) [11,45,46], and temperature of fermentation $[7,47,48]$. In the present study, it was possible to observe that temperature exerted an effect on the total production of VCs depending on the genetic background of the S. eubayanus strains. These changes have been previously reported in yeast of the genus Saccharomyces, where fermentation temperatures above $20^{\circ} \mathrm{C}$ modified the production of VCs in beer and wine [47]. A special case was the POF 4-VG, where no changes were observed in strain CL905.1, while in CL602.1, its content significantly increased when the fermentation temperature was increased $\left(12^{\circ}\right.$ to $\left.20^{\circ} \mathrm{C}\right)$. Most reports focused on the study of 4-VG have set out to find ways to reduce their production within the fermentation process by modulating precursors in the wort [8]; however, our results also demonstrate the impact of strain $\times$ temperature on the production of 4 -VG. From a physiological perspective, none of the parameters analyzed in this study may solely explain the changes in the VCs produced in S. eubayanus strains, suggesting a complex temperature $\times$ strain response under fermentative conditions. An example is the YAN content. During alcoholic fermentation, the cells import and metabolize the YAN in the wort together with other nutrients to produce biomass as well as VCs $[1,30,49,50]$. Therefore, depending on the amount and type of assimilated YAN, different VCs will be generated, thus determining the aromatic profiles of the fermented wort $[7,50]$. The YAN content can be separated into two groups, ammonium and amino acids. Ammonium is the primary nitrogen source in beer and wine yeasts [30]. Nitrogen consumption has been widely studied in wine yeast, establishing hierarchies in nitrogen source utilization [29]. For example, ammonium, glutamine, glutamate, and asparagine are considered good or preferred nitrogen sources. In S. eubayanus, we found that ammonium, aspartic acid, glutamic acid, serine, and threonine nitrogen sources were rapidly consumed and may represent the preferred nitrogen sources for wort fermentation. Interestingly, no differences were observed between strains in terms of such preferences, although temperature significantly impacted the nitrogen consumption rate at early timepoints.

\section{Conclusions}

Sensory properties of beer are influenced by the wide variety of VCs produced by yeast. The Patagonian populations of S. eubayanus comprise phenotypically distinct individuals, representing a niche of innovation for a wide range of volatile compounds in beer. Overall, S. eubayanus strains produce a more significant number of volatile compounds compared to a commercially available lager yeast. In this context, fermentation temperature plays an essential role, together with the genetic background of the S. eubayanus strain, in determining the VC profile of the resulting beer. The variation of the fermentation temperature can increase (CL905.1) or decrease (CL602.1) the amount and type of VCs depending on the strain, generating a fine-tuning mechanism on the total production of compounds that contribute to the complete and complex aromatic profile of the beer. HS-SPME-GC-MS is a handy tool to analyze the main VCs present in the fermented wort, allowing the reliable identification of the 
large variety of compounds produced during the fermentation process. In this way, the procedures that were followed in this report lay the foundation to study a wider set of strains, deepening our understanding of the catalog of VCs produced by S. eubayanus natural isolates, which have an enormous innovation potential.

Supplementary Materials: The following are available online at http://www.mdpi.com/2076-2607/8/5/755/s1. Figure S1 Fermentation profiles of S. eubayanus strains from central and southern Chile in beer wort. The fermentative kinetics of geographically-grouped wild yeast strains represent their fermentative capacity, as measured by $\mathrm{CO}_{2}$ loss (g/L). (a) Central strains: Region of Maule, Bío-Bío and La Araucanía. (b) Southern strains: Region of Los Ríos, Los Lagos, and Aysén. (c) Far southern strains: Region of Magallanes. As a negative control, we used beer wort without yeast cells. The commercial lager strain S. pastorianus W34/70 was used as a fermentation control. Figure S2. Pearson Correlation between the main volatile compounds identified and latitude. Each point depicts an average of the relative amount produced. Figure S3. Fermentation profiles of CL905.1 and CL602.1 strains in beer wort. The fermentative kinetics of both wild yeast strains represent their fermentative capacity, as measured by $\mathrm{CO}_{2} \operatorname{loss}(\mathrm{g} / \mathrm{L})$. (a) Fermentation at $12{ }^{\circ} \mathrm{C}$. (b) Fermentation at $20^{\circ} \mathrm{C}$. Table S1. Saccharomyces eubayanus isolates used in this work. Table S2. Presence/Absence table of Volatile compounds detected in S. eubayanus. Table S3. Presence/Absence of Volatile compounds detected in CL905.1 and CL602.1 strain at two fermentation temperatures. Table S4. Total YAN consumption. Table S5. YAN consumption at $24 \mathrm{~h}$ of Fermentation. Table S6. YAN consumption at $48 \mathrm{~h}$ of Fermentation. Table S7 YAN consumption at $168 \mathrm{~h}$ of Fermentation.

Author Contributions: K.U.: Investigation, Data curation, and Formal analysis; P.V.: Writing-Original Draft, Formal analysis and Methodology; R.S. (Rocio Santander): Data curation and Methodology; R.F.N.: Conceptualization, resources, and supervision, R.S. (Ricardo Salazar): Conceptualization, resources, and supervision, F.A.C.: Conceptualization, Methodology, Writing-Reviewing and Editing, and Funding acquisition. All authors have read and agreed to the published version of the manuscript.

Acknowledgments: F.A.C. was supported by the Comisión Nacional de Investigación Científica y Tecnológica CONICYT FONDECYT 1180161 and Millennium Institute for Integrative Biology (iBio). P.V. was funded by FONDECYT POSTDOCTORAL 3200575 and Universidad de Santiago de Chile 021843CR_POSTDOC. R.S. (Ricardo Salazar) was supported by CONICYT FONDECYT 1170352. R.F.N. was supported by FIC 'Transferencia Levaduras Nativas para Cerveza Artesanal' and CONICYT FONDECYT 1180917. K.U. was funded by USA1899-Vridei 021943CR-PAP Universidad de Santiago de Chile. R.S. (Rocio Santander) and HS-SPME-GC-MS analysis were supported by FONDEQUIP/GC MS/MS EQM 150084. We thank Michael Handford (Universidad de Chile) for language support.

Conflicts of Interest: The authors declare no conflict of interest.

\section{References}

1. Pires, E.J.; Teixeira, J.A.; Branyik, T.; Vicente, A.A. Yeast: The soul of beer's aroma-A review of flavour-active esters and higher alcohols produced by the brewing yeast. Appl. Microbiol. Biotechnol. 2014, 98, 1937-1949. [CrossRef] [PubMed]

2. Olaniran, A.O.; Hiralal, L.; Mokoena, M.P.; Pillay, B. Flavour-active volatile compounds in beer: Production, regulation and control. J. Inst. Brew. 2017, 123, 13-23. [CrossRef]

3. Gallone, B.; Mertens, S.; Gordon, J.L.; Maere, S.; Verstrepen, K.J.; Steensels, J. Origins, evolution, domestication and diversity of Saccharomyces beer yeasts. Curr. Opin. Biotechnol. 2018, 49, 148-155. [CrossRef] [PubMed]

4. Holt, S.; Miks, M.H.; de Carvalho, B.T.; Foulquie-Moreno, M.R.; Thevelein, J.M. The molecular biology of fruity and floral aromas in beer and other alcoholic beverages. FEMS Microbiol. Rev. 2019, 43, $193-222$. [CrossRef] [PubMed]

5. Baker, E.P.; Hittinger, C.T. Evolution of a novel chimeric maltotriose transporter in Saccharomyces eubayanus from parent proteins unable to perform this function. PLoS Genet. 2019, 15, e1007786. [CrossRef]

6. Gibson, B.; Geertman, J.A.; Hittinger, C.T.; Krogerus, K.; Libkind, D.; Louis, E.J.; Magalhaes, F.; Sampaio, J.P. New yeasts-new brews: Modern approaches to brewing yeast design and development. FEMS Yeast Res. 2017, 17. [CrossRef]

7. Dzialo, M.C.; Park, R.; Steensels, J.; Lievens, B.; Verstrepen, K.J. Physiology, ecology and industrial applications of aroma formation in yeast. FEMS Microbiol Rev. 2017, 41, S95-S128. [CrossRef]

8. Lentz, M. The Impact of Simple Phenolic Compounds on Beer Aroma and Flavor. Fermentation 2018, 4, 20. [CrossRef]

9. Cubillos, F.A.; Gibson, B.; Grijalva-Vallejos, N.; Krogerus, K.; Nikulin, J. Bioprospecting for brewers: Exploiting natural diversity for naturally diverse beers. Yeast 2019, 36, 383-398. [CrossRef] 
10. Giannetti, V.; Boccacci Mariani, M.; Torrelli, P.; Marini, F. Flavour component analysis by HS-SPME/GC-MS and chemometric modeling to characterize Pilsner-style Lager craft beers. Microchem. J. 2019, 149. [CrossRef]

11. Barbosa, C.; Mendes-Faia, A.; Mendes-Ferreira, A. The nitrogen source impacts major volatile compounds released by Saccharomyces cerevisiae during alcoholic fermentation. Int. J. Food Microbiol. 2012, 160, 87-93. [CrossRef] [PubMed]

12. Schneiderbanger, H.; Koob, J.; Poltinger, S.; Jacob, F.; Hutzler, M. Gene expression in wheat beer yeast strains and the synthesis of acetate esters. J. Inst. Brew. 2016, 122, 403-411. [CrossRef]

13. Bamforth, C.W. Progress in Brewing Science and Beer Production. Annu. Rev. Chem. Biomol. Eng. 2017, 8, 161-176. [CrossRef] [PubMed]

14. Meier-Dörnberg, T.; Hutzler, M.; Michel, M.; Methner, F.-J.; Jacob, F. The Importance of a Comparative Characterization of Saccharomyces cerevisiae and Saccharomyces pastorianus Strains for Brewing. Fermentation 2017, 3, 41. [CrossRef]

15. Hittinger, C.T.; Steele, J.L.; Ryder, D.S. Diverse yeasts for diverse fermented beverages and foods. Curr. Opin. Biotechnol. 2018, 49, 199-206. [CrossRef]

16. Holt, S.; Mukherjee, V.; Lievens, B.; Verstrepen, K.J.; Thevelein, J.M. Bioflavoring by non-conventional yeasts in sequential beer fermentations. Food Microbiol. 2018, 72, 55-66. [CrossRef]

17. Libkind, D.; Hittinger, C.T.; Valerio, E.; Goncalves, C.; Dover, J.; Johnston, M.; Goncalves, P.; Sampaio, J.P. Microbe domestication and the identification of the wild genetic stock of lager-brewing yeast. Proc. Natl. Acad. Sci. USA. 2011, 108, 14539-14544. [CrossRef]

18. Peris, D.; Sylvester, K.; Libkind, D.; Goncalves, P.; Sampaio, J.P.; Alexander, W.G.; Hittinger, C.T. Population structure and reticulate evolution of Saccharomyces eubayanus and its lager-brewing hybrids. Mol. Ecol. 2014, 23, 2031-2045. [CrossRef]

19. Langdon, Q.K.; Peris, D.; Eizaguirre, J.I.; Opulente, D.A.; Buh, K.V.; Sylvester, K.; Jarzyna, M.; Rodriguez, M.E.; Lopes, C.A.; Libkind, D.; et al. Postglacial migration shaped the genomic diversity and global distribution of the wild ancestor of lager-brewing hybrids. PLoS Genet. 2020, 16, e1008680. [CrossRef]

20. Bing, J.; Han, P.J.; Liu, W.Q.; Wang, Q.M.; Bai, F.Y. Evidence for a Far East Asian origin of lager beer yeast. Curr. Biol. 2014, 24, R380-R381. [CrossRef]

21. Gayevskiy, V.; Goddard, M.R. Saccharomyces eubayanus and Saccharomyces arboricola reside in North Island native New Zealand forests. Environ. Microbiol. 2016, 18, 1137-1147. [CrossRef] [PubMed]

22. Nespolo, R.F.; Villarroel, C.A.; Oporto, C.I.; Tapia, S.M.; Vega, F.; Urbina, K.; De Chiara, M.; Mozzachiodi, S.; Mikhalev, E.; Thompson, D.; et al. An Out-of-Patagonia migration explains the worldwide diversity and distribution of Saccharomyces eubayanus lineages. PLoS Genet. 2020. [CrossRef] [PubMed]

23. Mardones, W.; Villarroel, C.A.; Krogerus, K.; Tapia, S.M.; Urbina, K.; Oporto, C.I.; O’Donnell, S.; Minebois, R.; Nespolo, R.; Fischer, G.; et al. Molecular profiling of beer wort fermentation diversity across natural Sacharomyces eubayanus isolates. Microb. Biotechnol. 2020. [CrossRef] [PubMed]

24. Sampaio, J.P.; Goncalves, P. Natural populations of Saccharomyces kudriavzevii in Portugal are associated with oak bark and are sympatric with S. cerevisiae and S. paradoxus. Appl. Environ. Microbiol. 2008, 74, 2144-2152. [CrossRef] [PubMed]

25. White, C.; Zainasheff, J. Yeast: The Practical Guide to Beer Fermentation; Brewers Publications: Boulder, CO, USA, 2010.

26. Santander, R.; Creixell, W.; Sánchez, E.; Tomic, G.; Silva, J.R.; Acevedo, C.A. Recognizing Age at Slaughter of Cattle from Beef Samples Using GC/MS-SPME Chromatographic Method. Food Bioprocess. Technol. 2012, 6, 3345-3352. [CrossRef]

27. R Development Core Team. R: A Lenguage and Environment for Statisctical Computing; R. Foundation for Statistical Computing, 2008. Available online: http://finzi.psych.upenn.edu/R/library/dplR/doc/intro-dplR. pdf (accessed on 18 May 2020).

28. Jara, M.; Cubillos, F.A.; Garcia, V.; Salinas, F.; Aguilera, O.; Liti, G.; Martinez, C. Mapping genetic variants underlying differences in the central nitrogen metabolism in fermenter yeasts. PLOS ONE 2014, 9, e86533. [CrossRef]

29. Crepin, L.; Nidelet, T.; Sanchez, I.; Dequin, S.; Camarasa, C. Sequential use of nitrogen compounds by Saccharomyces cerevisiae during wine fermentation: A model based on kinetic and regulation characteristics of nitrogen permeases. Appl. Environ. Microbiol. 2012, 78, 8102-8111. [CrossRef] 
30. Gobert, A.; Tourdot-Marechal, R.; Sparrow, C.; Morge, C.; Alexandre, H. Influence of nitrogen status in wine alcoholic fermentation. Food Microbiol. 2019, 83, 71-85. [CrossRef]

31. Gallone, B.; Steensels, J.; Prahl, T.; Soriaga, L.; Saels, V.; Herrera-Malaver, B.; Merlevede, A.; Roncoroni, M.; Voordeckers, K.; Miraglia, L.; et al. Domestication and Divergence of Saccharomyces cerevisiae Beer Yeasts. Cell 2016, 166, 1397-1410 e1316. [CrossRef]

32. Bellut, K.; Arendt, E.K. Chance and Challenge: Non-Saccharomyces Yeasts in Nonalcoholic and Low Alcohol Beer Brewing-A Review. J. Am. Soc. Brew. Chem. 2019, 77, 77-91. [CrossRef]

33. Rodriguez, M.E.; Orozco, H.; Cantoral, J.M.; Matallana, E.; Aranda, A. Acetyltransferase SAS2 and sirtuin SIR2, respectively, control flocculation and biofilm formation in wine yeast. FEMS Yeast Res. 2014, 14, 845-857. [CrossRef] [PubMed]

34. Pinho, O.; Ferreira, I.M.; Santos, L.H. Method optimization by solid-phase microextraction in combination with gas chromatography with mass spectrometry for analysis of beer volatile fraction. J. Chromatogr. A 2006, 1121, 145-153. [CrossRef] [PubMed]

35. Bokulich, N.A.; Bamforth, C.W. The microbiology of malting and brewing. Microbiol. Mol. Biol. Rev. 2013, 77, 157-172. [CrossRef]

36. Krogerus, K.; Magalhaes, F.; Vidgren, V.; Gibson, B. Novel brewing yeast hybrids: Creation and application. Appl. Microbiol. Biotechnol. 2017, 101, 65-78. [CrossRef] [PubMed]

37. Olaniran, A.O.; Maharaj, Y.R.; Pillay, B. Effects of fermentation temperature on the composition of beer volatile compounds, organoleptic quality and spent yeast density. Electro. J. Biotechnol. 2011, 14. [CrossRef]

38. Hiralal, L.; Olaniran, A.O.; Pillay, B. Aroma-active ester profile of ale beer produced under different fermentation and nutritional conditions. J. Biosci. Bioeng. 2014, 117, 57-64. [CrossRef]

39. Tokpohozin, S.E.; Fischer, S.; Becker, T. Selection of a new Saccharomyces yeast to enhance relevant sorghum beer aroma components, higher alcohols and esters. Food Microbiol. 2019, 83, 181-186. [CrossRef]

40. Rossouw, D.; Naes, T.; Bauer, F.F. Linking gene regulation and the exo-metabolome: A comparative transcriptomics approach to identify genes that impact on the production of volatile aroma compounds in yeast. BMC Genom. 2008, 9, 530. [CrossRef]

41. Eder, M.; Sanchez, I.; Brice, C.; Camarasa, C.; Legras, J.L.; Dequin, S. QTL mapping of volatile compound production in Saccharomyces cerevisiae during alcoholic fermentation. BMC Genom. 2018, 19, 166. [CrossRef]

42. Lee, K.; Hahn, J.S. Interplay of Aro80 and GATA activators in regulation of genes for catabolism of aromatic amino acids in Saccharomyces cerevisiae. Mol. Microbiol. 2013, 88, 1120-1134. [CrossRef]

43. Saerens, S.M.; Delvaux, F.; Verstrepen, K.J.; Van Dijck, P.; Thevelein, J.M.; Delvaux, F.R. Parameters affecting ethyl ester production by Saccharomyces cerevisiae during fermentation. Appl. Environ. Microbiol. 2008, 74, 454-461. [CrossRef] [PubMed]

44. Curiel, J.A.; Salvado, Z.; Tronchoni, J.; Morales, P.; Rodrigues, A.J.; Quiros, M.; Gonzalez, R. Identification of target genes to control acetate yield during aerobic fermentation with Saccharomyces cerevisiae. Microb. Cell Fact. 2016, 15, 156. [CrossRef] [PubMed]

45. Barbosa, C.; Falco, V.; Mendes-Faia, A.; Mendes-Ferreira, A. Nitrogen addition influences formation of aroma compounds, volatile acidity and ethanol in nitrogen deficient media fermented by Saccharomyces cerevisiae wine strains. J. Biosci. Bioeng. 2009, 108, 99-104. [CrossRef] [PubMed]

46. Bely, M.; Rinaldi, A.; Dubourdieu, D. Influence of assimilable nitrogen on volatile acidity production by Saccharomyces cerevisiae during high sugar fermentation. J. Biosci. Bioeng. 2003, 96, 507-512. [CrossRef]

47. Beltran, G.; Novo, M.; Guillamon, J.M.; Mas, A.; Rozes, N. Effect of fermentation temperature and culture media on the yeast lipid composition and wine volatile compounds. Int. J. Food Microbiol. 2008, 121, 169-177. [CrossRef]

48. Kodama, Y.; Omura, F.; Miyajima, K.; Ashikari, T. Control of Higher Alcohol Production by Manipulation of the BAP2 Gene in Brewing Yeast. J. Am. Soc. Brew. Chem. 2018, 59, 157-162. [CrossRef]

49. Deed, R.C.; Deed, N.K.; Gardner, R.C. Transcriptional response of Saccharomyces cerevisiae to low temperature during wine fermentation. Antonie. Van. Leeuwenhoek. 2015, 107, 1029-1048. [CrossRef]

50. Hill, A.; Stewart, G. Free Amino Nitrogen in Brewing. Fermentation 2019, 5, 22. [CrossRef]

(C) 2020 by the authors. Licensee MDPI, Basel, Switzerland. This article is an open access article distributed under the terms and conditions of the Creative Commons Attribution (CC BY) license (http://creativecommons.org/licenses/by/4.0/). 